\title{
Blonanserin Augmentation of Atypical Antipsychotics in Patients with Schizophrenia-Who Benefits from Blonanserin Augmentation?: An Open-Label, Prospective, Multicenter Study
}

\author{
Young Sup Woo', Joo Eon Park², Do-Hoon Kim³ ${ }^{3}$ Inki Sohn², Tae-Yeon Hwang ${ }^{4}$, Young-Min Park ${ }^{5}$, \\ Duk-In Jon ${ }^{6}$, Jong-Hyun Jeong ${ }^{1}$, and Won-Myong Bahk ${ }^{1 凶}$ \\ 1Department of Psychiatry, College of Medicine, The Catholic University of Korea, Seoul, Republic of Korea \\ ${ }^{2}$ Department of Psychiatry, Keyo Hospital, Keyo Medical Foundation, Uiwang, Republic of Korea \\ ${ }^{3}$ Department of Psychiatry, Hallym University Medical Center, Chuncheon Sacred Heart Hospital, Chuncheon, Republic of Korea \\ ${ }^{4} \mathrm{WHO}$ Collaborating Center of Yongin Mental Hospital, Yongin, Republic of Korea \\ ${ }^{5}$ Department of Psychiatry, Ilsan Paik Hospital, College of Medicine, Inje University, Goyang, Republic of Korea \\ ${ }^{6}$ Department of Psychiatry, College of Medicine, Hallym University, Anyang, Republic of Korea
}

Objective The purpose of this study was to investigate the efficacy and tolerability of atypical antipsychotics (AAPs) with augmentation by blonanserin in schizophrenic patients.

Methods A total of 100 patients with schizophrenia who were partially or completely unresponsive to treatment with an AAP were recruited in this 12-week, open-label, non-comparative, multicenter study. Blonanserin was added to their existing AAP regimen, which was maintained during the study period. Efficacy was primarily evaluated using the Positive and Negative Syndrome Scale (PANSS) at baseline and at weeks 2, 4, 8, and 12. Predictors for PANSS response ( $\geq 20 \%$ reduction) were investigated.

Results The PANSS total score was significantly decreased at 12 weeks of blonanserin augmentation $(-21.0 \pm 18.1, \mathrm{~F}=105.849, \mathrm{p}<0.001)$. Moreover, $51.0 \%$ of participants experienced a response at week 12. Premature discontinuation of blonanserin occurred in 17 patients (17.0\%); 4 of these patients dropped out due to adverse events. The patients who benefited the most from blonanserin were those with severe symptoms despite a treatment with a higher dose of AAP.

Conclusion Blonanserin augmentation could be an effective strategy for patients with schizophrenia who were partially or completely unresponsive to treatment with an AAP.

Psychiatry Investig 2016;13(4):458-467

Key Words Blonanserin, Schizophrenia, Augmentation, Treatment response, Antipsychotics.

\section{INTRODUCTION}

Schizophrenia is a chronic and disabling mental disorder characterized by severe behavioral symptoms that commonly require life-long therapeutic intervention. While antipsychotic medications are the cornerstone of schizophrenia treatment, the effect of treatment is limited by unfavorable side effects,

Received: January 15, 2016 Revised: February 12, 2016 Accepted: March 7, 2016 Available online: June 1, 2016

$\triangle$ Correspondence: Won-Myong Bahk, MD, PhD

Department of Psychiatry, Yeouido St. Mary's Hospital, College of Medicine, The Catholic University of Korea, 10 63-ro, Yeongdeungpo-gu, Seoul 07345, Republic of Korea

Tel: +82-2-3779-1250, Fax: +82-2-780-6577, E-mail: wmbahk@catholic.ac.kr

(a) This is an Open Access article distributed under the terms of the Creative Commons Attribution Non-Commercial License (http://creativecommons.org/licenses/by$\mathrm{nc} / 3.0$ ) which permits unrestricted non-commercial use, distribution, and reproduction in any medium, provided the original work is properly cited. nonresponse to medication, and modest efficacy on negative symptoms. ${ }^{1}$ Up to $70 \%$ of patients do not achieve full remission, even when taking antipsychotic medications as recommended. ${ }^{2}$ This limited therapeutic effect of antipsychotic medications continues to be a significant clinical and public health problem. ${ }^{3,4}$

In order to overcome the limited effectiveness of antipsychotic drugs, polypharmacy is very common in the treatment of schizophrenia. In fact, it has been reported that $4.1-48.0 \%$ of patients use two or more medications, with most studies report a prevalence of between $10 \%$ and $30 \%{ }^{5,6}$ In a recent study, over $20 \%$ of schizophrenic patients in Korea had been prescribed antipsychotic polypharmacy. ${ }^{5}$ Polypharmacy is popular despite the consensus statements that recommend monotherapy as the standard treatment for schizophrenia, ${ }^{7-10}$ and the fact that there is little clinical data to support it. ${ }^{11}$ Moreover, 
there are concerns about the long-term safety, ${ }^{12,13}$ mortality, ${ }^{14,15}$ and increased cost associated with antipsychotics polypharmacy. $^{16}$

However, antipsychotic polypharmacy could be effective for patients with schizophrenia when a single agent does not adequately relieve symptoms. Pharmacologically, antipsychotic combinations seek to achieve greater therapeutic potential by optimizing dopamine D2 receptor occupancy or increasing activity across a wider range of receptors related to the pathogenesis of schizophrenia. ${ }^{17,18}$ In a review by Chan and Sweeting $^{19}$ on the combination of non-clozapine second generation antipsychotics with possibly complementary receptor profiles, they reported that some symptom improvement had occurred. Also, beneficial effects of antipsychotic polypharmacy was reported in small, open-label trials with olanzapine plus risperidone ${ }^{20}$ and olanzapine plus amisulpride. ${ }^{21}$ Moreover, in a meta-analysis, Correll et al. ${ }^{6}$ presented findings arguing that antipsychotic polypharmacy may have a clinical advantage over standard (non-clozapine) monotherapy in nonresponsive patients. They also noted that more studies combining non-clozapine atypical antipsychotics (AAPs) with each other, which is a strategy often used in clinical practice, are required to explore the merits of combining antipsychotics in the acute phase instead of waiting at least 10 weeks to declare that nonresponse has occurred. ${ }^{6}$

Blonanserin is a well-known second-generation antipsychotic commonly used in Japan and Korea with a unique pharmacological receptor profile; it has a higher dopamine D2 receptor occupancy $\left(\mathrm{K}_{\mathrm{i}}=0.142 \mathrm{nM}\right)$ and lower serotonin $2 \mathrm{~A}$ receptor-blocking activity $\left(\mathrm{K}_{\mathrm{i}}=0.812 \mathrm{nM}\right)$ than other second generation antipsychotics. ${ }^{22}$ It also has weak dopamine D1 and weak adrenergic alpha1 receptor blocking activity. ${ }^{23}$ The effectiveness of blonanserin monotherapy in the treatment of schizophrenia has been demonstrated by several clinical studies $^{24-27}$ and a meta-analysis. ${ }^{28}$ In a study with Korean schizophrenic patients, ${ }^{25}$ blonanserin showed comparable effectiveness with risperidone, was more tolerable, and had a better safety profile, particularly with respect to prolactin elevation. Moreover, blonanserin showed the lowest discontinuation rate due to intolerance than other AAPs including quetiapine, aripiprazole, risperidone, perospirone, and olanzapine. ${ }^{29}$ These results suggest that blonanserin may have advantages in tolerability, one of the most disadvantageous factors for antipsychotic polypharmacy. ${ }^{30}$

The goals of this study were to test the hypothesis that blonanserin augmentation would improve psychotic symptoms and be well tolerated in patients who failed to respond to another AAP and to identify factors that can be used to predict a patients' response to blonanserin augmentation therapy.

\section{METHODS}

\section{Study design and sample}

This was an open-label, prospective, multicenter, 12-week study that included 100 patients. The patients were diagnosed with schizophrenia according to DSM-IV-TR criteria and did not respond or only partially responded to an AAP treatment. This study was conducted at 7 centers in Korea, including 5 university hospitals and two psychiatric hospitals.

After at least 6 weeks of treatment with recommended dose of AAPs, patients completed the 18-item Korean version of the brief psychiatric rating scale (BPRS, items scored on a 1-7 scale). Patients scoring 43 or more were classified as non-responders or partial responders. ${ }^{31}$ At the study entry, participants were $\geq 20$ and $\leq 70$ years of age and were being treated with one AAP: aripiprazole, clozapine, olanzapine, paliperidone, or risperidone. These AAPs were selected because of their pharmacokinetic properties. Blonanserin is known to be metabolized predominantly via the cytochrome P450 (CYP) enzyme CYP3A4 and does not inhibit any key CYP enzymes. ${ }^{32}$ Therefore, blonanserin is considered unlikely to have any significant clinical pharmacokinetic interactions with antipsychotics that are mainly metabolized by CYP1A2 (clozapine, olanzapine) or CYP2D6 (aripiprazole, risperidone); ${ }^{33}$ paliperidone does not undergo significant hepatic metabolism. . $^{32,34}$ Among the exclusion criteria were pregnancy or lactation, a medical condition that could interfere with everyday life activities, and a diagnosis of any Axis I disorder other than schizophrenia. Patients were excluded from participation if they had been prescribed blonanserin before the study, had been prescribed a depot of antipsychotics within 30 days of the study; were currently being treated with two or more antipsychotics; or were known to be treatment resistant. All patients gave informed consent before participation in the study.

\section{Medication}

The blonanserin was recommended to be dosed flexibly within the range of $8-24 \mathrm{mg} /$ day. During the study period, it was recommended that the AAP dose to be kept constant. Concomitant treatment with ongoing mood stabilizers/anticonvulsants or antidepressants was permitted if the patient had been on a stable dose for at least 2 weeks prior to enrollment, but it was requested that the dose not be changed during the study period. Patients were not given any other antipsychotics, mood stabilizers/anticonvulsants, or antidepressants during the study. Benzodiazepines, anti-Parkinsonian agents, and hypnotics were permitted at the discretion of the investigator.

\section{Efficacy measures}

Psychiatric symptoms were evaluated with the Korean ver- 
sion of BPRS, the Positive and Negative Syndrome Scale (PANSS), and the Clinical Global Impressions-Severity Scale (CGI-S) at baseline and at weeks 2, 4, 8, and 12. The primary efficacy assessment was defined as mean change from baseline to week 12 on the PANSS total score. Additional efficacy measures included response rates with PANSS and BPRS, mean change in PANSS-positive, negative, and general subscale, BPRS, and CGI-S scores. Response was defined as a decrease in the PANSS and BPRS total scores $\geq 20 \%{ }^{28}$

\section{Safety and tolerability}

Safety assessments included monitoring of vital signs and weight at baseline and week 12, a physical examination, and reported adverse events at each visit. At each visit, extrapyramidal symptoms were assessed using the Simpson-Angus Scale (SAS) and the Barnes Akathisia Rating Scale (BARS). The Abnormal Involuntary Movements Scale (AIMS) was applied to assess abnormal involuntary movement.

\section{Statistical analysis}

Data were analyzed on an intent-to-treat (ITT) group, and the last-observation-carried forward (LOCF) method was applied for endpoint analysis. The data included all patients who provided a baseline and at least one post-baseline data measurement. All subjects who received at least one dose of the study medication were included in the safety analysis.

Categorical variables are presented as absolute number and relative frequencies (\%), and nominal variables are described as mean \pm standard deviation. Data for each psychometric scale and scale for adverse event scores were analyzed by repeated measure analysis of variance (RM-ANOVA). A GreenhouseGeisser correction was used to test for non-sphericity. The chi-square test or Fisher's exact test was used to analyze categorical variables, and a paired t-test was performed for variables measured at baseline and endpoint.

We also investigated the predictors of response to blonanserin augmentation by comparing responders and non-responders with an independent t-test, chi-square test, or Fisher's exact test. A binary logistic regression analysis was conducted with age, sex, and variables with significance $(\mathrm{p}<0.05)$ or trend toward significance $(\mathrm{p}<0.10)$ on univariate analyses with response as an independent variable (i.e., responders and non-responders). All statistical tests were two-tailed with a significance level of 0.05 .

\section{Ethics}

The study was conducted according to the Declaration of Helsinki and Good Clinical Practices. Written informed consent was obtained from all subjects after the subjects were given an extensive explanation of the nature and procedures of the study. The study protocol was approved by the Institutional Review or Ethics Committees at each study site.

\section{RESULTS}

\section{Patients and medications}

The number of participants who completed the 12-week treatment was 83 (83.0\%). The demographic and clinical characteristics of the subjects at baseline are presented in Table 1. The mean chlorpromazine equivalent dose ${ }^{35}$ of concomitant AAPs at baseline was $516.4 \pm 153.6 \mathrm{mg} /$ day. The blonanserin dose at each visit is shown in Figure 1. The mean dose of blonanserin during the study period was $11.7 \pm 5.8 \mathrm{mg} /$ day. There were 19 (19.0\%) subjects who were treated with concomitant mood stabilizer/anticonvulsants and 8 (8.0\%) who were treated with concomitant antidepressants at baseline.

\section{Efficacy and tolerability in the entire sample}

The mean total scores on the PANSS and BPRS significantly decreased from baseline to week $12(-21.0 \pm 18.1, \mathrm{p}<0.001$ and $-14.0 \pm 11.6, \mathrm{p}<0.001$, respectively; Table 2). All three subscales of PANSS (positive, negative, and general psychopathology) also decreased significantly from baseline to endpoint (all $\mathrm{p}<0.001$, Table 2). The CGI-S score decreased from $4.7 \pm 1.1$, which means 'moderate to markedly ill', to $3.8 \pm 1.1$, which means 'mildly to moderately ill.' The number of responders who showed a reduction in PANSS and BPRS scores of $20 \%$ or greater at week 12 were 51 (51.0\%) and 57 (57.0\%), respectively (Figure 2).

Seventeen participants (17.0\%) withdrew from the study prematurely. Six patients $(6.0 \%)$ were lost to follow-up, 4 patients (4.0\%) discontinued due to adverse events (two cases of akathisia, one case of weight gain, and one case of epidural hemorrhage from a fall), two patients $(2.0 \%)$ due to insufficient response, non-compliance, and/or protocol violation, and one patient (1.0\%) discontinued the study by withdrawal of consent. The adverse events frequently reported ( $\geq 3 \%$ ) during the 12 weeks of the study are listed in Table 3. A total of 50 patients (50.0\%) reported 225 adverse events. Among them, 41 adverse events in 19 patients were newly developed adverse events or worsening of existing adverse events after blonanserin augmentation was initiated. The severity of every reported adverse event was mild $(79.1 \%, \mathrm{n}=178)$ or moderate $(20.4 \%$, $\mathrm{n}=46$ ), except for one severe case of epidural hemorrhage. The results by RM-ANOVA showed that the scores on SAS (F= 1.476, $\mathrm{p}=0.232)$, BARS $(\mathrm{F}=0.400, \mathrm{p}=0.672)$, and AIMS $(\mathrm{F}=$ $1.204, \mathrm{p}=0.305$ ) (Figure 3 ) were not significantly changed during study period.

Blood pressure, body weight, and body mass index (BMI) were compared between baseline and endpoint. Systolic ( $\mathrm{p}>$ 
0.999) and diastolic blood pressure $(\mathrm{p}=0.254)$ were not significantly different between the two time points (data not shown). Weight significantly increased from $66.7 \pm 14.8 \mathrm{~kg}$ at baseline to $68.0 \pm 15.6 \mathrm{~kg}$ at week $12(\mathrm{p}=0.001)$. Consequently, BMI also significantly increased from $24.6 \pm 4.1 \mathrm{~kg} / \mathrm{m}^{2}$ to $25.1 \pm 4.4 \mathrm{~kg} /$ $\mathrm{m}^{2}$. For each concomitant antipsychotics groups, patients treated with blonanserin as an augmentation to olanzapine showed significant increase in weight from $66.3 \pm 13.0 \mathrm{~kg}$ at baseline to
$68.0 \pm 14.2 \mathrm{~kg}$ at week $12(\mathrm{p}=0.002)$. There was no significant change in weight during study period in patients treated with other concomitant antipsychotics and blonanserin (data not shown). Ten patients (10.0\%) experienced significant ( $\geq 7 \%)$ weight change during the study period. Among them, 9 patients ( 8 patients treated with olanzapine and blonanserin, and 1 patient treated with risperidone and blonanserin) gained weight and one patient lost weight.

Table 1. Baseline demographic and clinical characteristics

\begin{tabular}{|c|c|}
\hline & Total patients $(\mathrm{N}=100)$, mean $\pm \mathrm{SD}$ or $\mathrm{N}(\%)$ \\
\hline Age (years) & $43.1 \pm 11.8$ \\
\hline Gender (male) & $47(47.0)$ \\
\hline Years of schooling & $12.6 \pm 3.1$ \\
\hline Married & $27(27.0)$ \\
\hline Living alone & $14(14.0)$ \\
\hline Employed & $20(20.0)$ \\
\hline \multicolumn{2}{|l|}{ Socio-economic status } \\
\hline High & $8(8.0)$ \\
\hline Middle & $65(65.0)$ \\
\hline Low & $27(27.0)$ \\
\hline Age at onset & $29.1 \pm 10.6$ \\
\hline Inpatient & $48(48.0)$ \\
\hline Number of past psychiatric hospitalizations & $3.6 \pm 3.9$ \\
\hline Family history of psychiatric illness & $13(13.0)$ \\
\hline \multicolumn{2}{|l|}{ Subtypes } \\
\hline Paranoid & $65(65.0)$ \\
\hline Disorganized & $3(3.0)$ \\
\hline Catatonic & $1(1.0)$ \\
\hline Undifferentiated & $31(31.0)$ \\
\hline Presence of a comorbid medical illness & $33(33.0)$ \\
\hline \multicolumn{2}{|l|}{ Baseline scores } \\
\hline BPRS & $60.0 \pm 13.9$ \\
\hline PANSS-total & $104.5 \pm 25.0$ \\
\hline PANSS-positive & $26.5 \pm 7.0$ \\
\hline PANSS-negative & $25.0 \pm 7.5$ \\
\hline PANSS-general & $53.3 \pm 12.8$ \\
\hline CGI-S & $4.7 \pm 1.1$ \\
\hline GAF & $40.0 \pm 14.2$ \\
\hline Mild to moderate severity (PANSS $\leq 85$ ) & $24(24.0)$ \\
\hline \multicolumn{2}{|l|}{ Concomitant antipsychotics } \\
\hline Aripiprazole & $4(4.0)$ \\
\hline Clozapine & $12(12.0)$ \\
\hline Olanzapine & $68(68.0)$ \\
\hline Risperidone/paliperidone & $16(16.0)$ \\
\hline
\end{tabular}

SD: standard deviation, BPRS: Brief Psychiatric Rating Scale, PANSS: Positive and Negative Syndrome Scale, CGI-S: Clinical Global Impression Scale-Severity, GAF: Global Assessment of Functioning 


\section{Characteristics of responders and non-responders}

Table 4 shows a comparison of baseline characteristics between people who responded to blonanserin augmentation vs. those who did not. Responders who showed a decrease in their total PANSS score of $20 \%$ or more exhibited a higher baseline BPRS total score $(\mathrm{p}=0.043)$ and a higher baseline PANSS total score $(\mathrm{p}=0.038)$. In addition, responders' scores on the PANSSpositive section ( $\mathrm{p}=0.025)$ and the general psychopathology $(\mathrm{p}=0.016)$ section at baseline were significantly greater than non-responders' scores. Among the responders, $60.8 \%(\mathrm{n}=31)$ were inpatients, while only $34.7 \%(n=17)$ of the non-responders were inpatients $(\mathrm{p}=0.009)$. Baseline symptom severity was

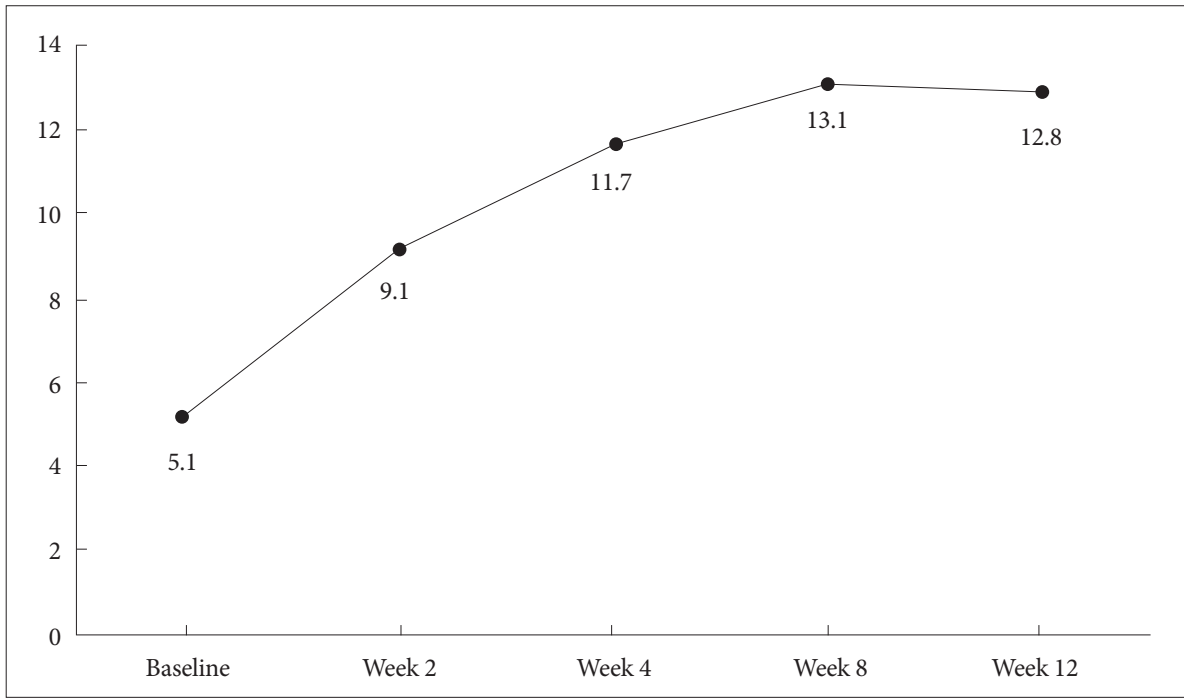

Figure 1. Blonanserin dose at each visit (mg/day).

Table 2. Changes of PANSS, BPRS, and CGI-S scores from baseline to week 12 in patients with schizophrenia

\begin{tabular}{|c|c|c|c|c|c|c|c|}
\hline & \multirow{2}{*}{$\begin{array}{c}\text { Baseline score } \\
(\text { mean } \pm \mathrm{SD})\end{array}$} & \multicolumn{4}{|c|}{ Mean changes from baseline (mean \pm SD) } & \multirow{2}{*}{ F-value } & \multirow{2}{*}{ Significance } \\
\hline & & Week 2 & Week 4 & Week 8 & Week 12 & & \\
\hline PANSS-total score & $104.5 \pm 25.0$ & $-7.0 \pm 10.2$ & $-12.3 \pm 12.8$ & $-17.2 \pm 16.3$ & $-21.0 \pm 18.1$ & 105.849 & $<0.001$ \\
\hline PANSS-positive & $26.5 \pm 7.0$ & $-2.2 \pm 3.7$ & $-3.7 \pm 4.7$ & $-5.2 \pm 5.7$ & $-6.3 \pm 6.0$ & 82.618 & $<0.001$ \\
\hline PANSS-negative & $25.0 \pm 7.5$ & $-1.2 \pm 1.9$ & $-2.1 \pm 2.5$ & $-2.9 \pm 3.7$ & $-3.8 \pm 3.8$ & 59.689 & $<0.001$ \\
\hline PANSS-general & $53.3 \pm 12.8$ & $-3.6 \pm 6.3$ & $-6.5 \pm 7.4$ & $-9.2 \pm 9.0$ & $-11.0 \pm 10.1$ & 88.901 & $<0.001$ \\
\hline BPRS & $60.0 \pm 13.9$ & $-5.0 \pm 7.7$ & $-8.5 \pm 9.2$ & $-11.8 \pm 10.8$ & $-14.0 \pm 11.6$ & 105.976 & $<0.001$ \\
\hline CGI-S & $4.7 \pm 1.1$ & $-0.5 \pm 0.7$ & $-0.6 \pm 0.9$ & $-0.8 \pm 1.0$ & $-1.0 \pm 1.1$ & 54.635 & $<0.001$ \\
\hline
\end{tabular}

PANSS: Positive and Negative Syndrome Scale, BPRS: Brief Psychiatric Rating Scale, CGI-S: Clinical Global Impression Scale-Severity, SD: standard deviation

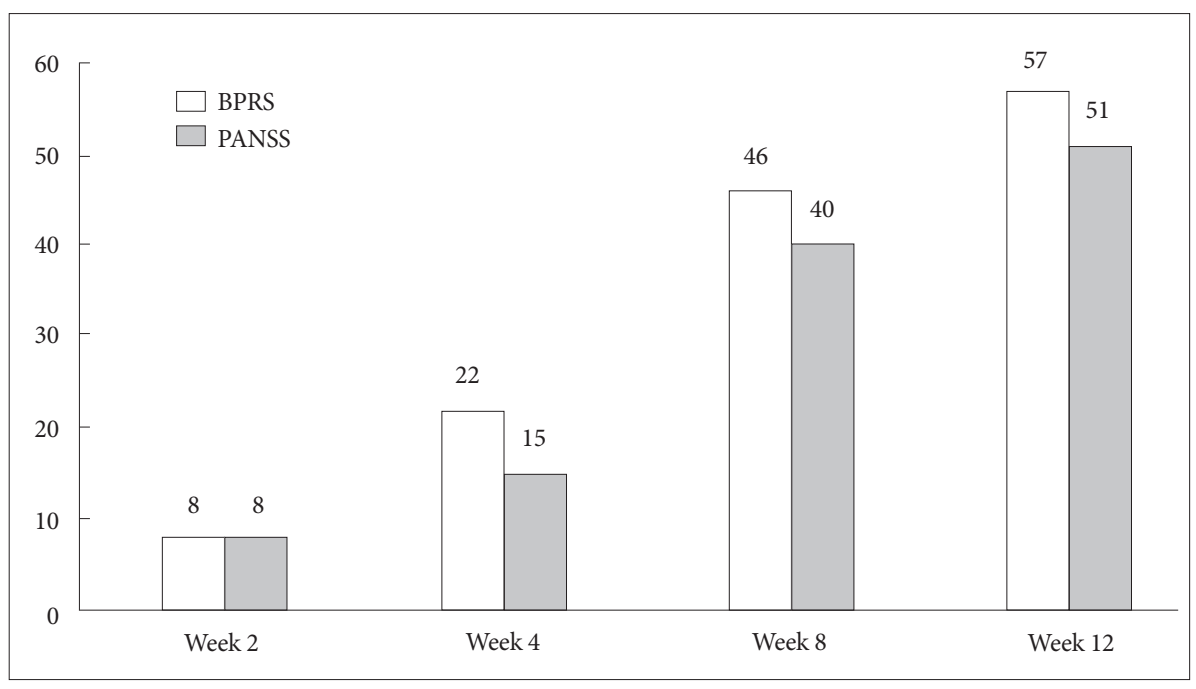

Figure 2. Response rate $(\geq 20 \%$ reduction) at each visit $(\mathrm{N}=100)$. BPRS: Brief Psychiatric Rating Scale, PANSS: Positive and Negative Syndrome Scale. 
categorized into mild to moderate symptoms (PANSS total score $\leq 85$ ) and severe symptoms (PANSS total score $>85$ ). Only $9.8 \%(n=5)$ of responders exhibited mild to moderate severity, while the majority of responders exhibited severe baseline symptoms. In contrast, $38.8 \%(n=19)$ of non-responders had mild to moderate baseline symptoms and only $61.2 \%$ of nonresponders had severe baseline symptoms ( $\mathrm{p}=0.001)$. Reflecting this difference in severity, the mean dose of blonanserin during the study period was $13.9 \pm 6.3 \mathrm{mg}$ /day for responders and $9.4 \pm 4.3 \mathrm{mg} /$ day for non-responders $(\mathrm{p}<0.001)$. Mean chlorpromazine equivalent dose of concomitant AAPs was also significantly different between the two groups $(\mathrm{p}<0.001)$; responders were administered $562.2 \pm 133.1 \mathrm{mg} /$ day while non-responders took $437.6 \pm 193.9 \mathrm{mg} /$ day. However, the starting dose of blonanserin in responders $(5.0 \pm 1.9 \mathrm{mg} /$ day $)$ was not significantly different from that of non-responders $(5.3 \pm 2.8$ $\mathrm{mg} / \mathrm{day}, \mathrm{p}=0.476$ ). Use of other concomitant medication was not significantly different between the groups (Table 4). At baseline, $39.2 \%(n=20)$ of responders reported one or more adverse event from their AAP and $22.4 \%(n=11)$ of non-responders reported an adverse event from their AAP $(p=0.070)$.
Based on logistic regression analysis with covariates as age, sex, hospitalization, PANSS severity, PANSS-positive score, general subscale score, use of clozapine, dosing for both blonanserin and concomitant AAP (divided at the median value to achieve high and low dose groups), and the presence of baseline adverse events, there were two significant predictors of response (Table 5): severe (PANSS $>85$ ) baseline symptoms $(\mathrm{OR}=10.3,95 \% \mathrm{CI}=1.9-56.0, \mathrm{p}=0.007)$ and high chlorpromazine equivalent dose ( $>600 \mathrm{mg} /$ day) of the concomitant AAP $(\mathrm{OR}=4.6,95 \% \mathrm{CI}=1.4-15.5, \mathrm{p}=0.014)$.

\section{DISCUSSION}

As far as we can tell, this is the first prospective study to investigate the effectiveness and tolerability of blonanserin augmentation in schizophrenic patients. In the present study, blonanserin augmentation improved symptoms in schizophrenic patients who failed to respond sufficiently to treatment with an AAP, especially in patients with severe symptoms and treated with relatively higher dose of the AAP.

There have been only limited studies on the efficacy of aug-

Table 3. Adverse events during study period $(\geq 3 \%, N=100)$

\begin{tabular}{lccc}
\hline \multicolumn{1}{c}{ Adverse event } & Total, N (\%) & Baseline, N (\%) & Newly developed during study period, N (\%) \\
\hline Constipation & $20(20.0)$ & $17(17.0)$ & $3(3.0)$ \\
Akathisia & $10(10.0)$ & $4(4.0)$ & $6(6.0)$ \\
Weight gain & $9(9.0)$ & 0 & $9(9.0)$ \\
Tremor & $8(8.0)$ & $5(5.0)$ & $3(3.0)$ \\
Rigidity & $6(6.0)$ & $4(4.0)$ & $2(2.0)$ \\
Bradykinesia & $4(4.0)$ & $3(3.0)$ & $4(1.0)$ \\
Sialorrhoea & $5(5.0)$ & $1(1.0)$ & $2(2.0)$ \\
Dyskinesia & $3(3.0)$ & $1(1.0)$ & $3(3.0)$ \\
Nausea & $4(4.0)$ & 0 & $3(3.0)$ \\
Paresthesia & $3(3.0)$ & &
\end{tabular}

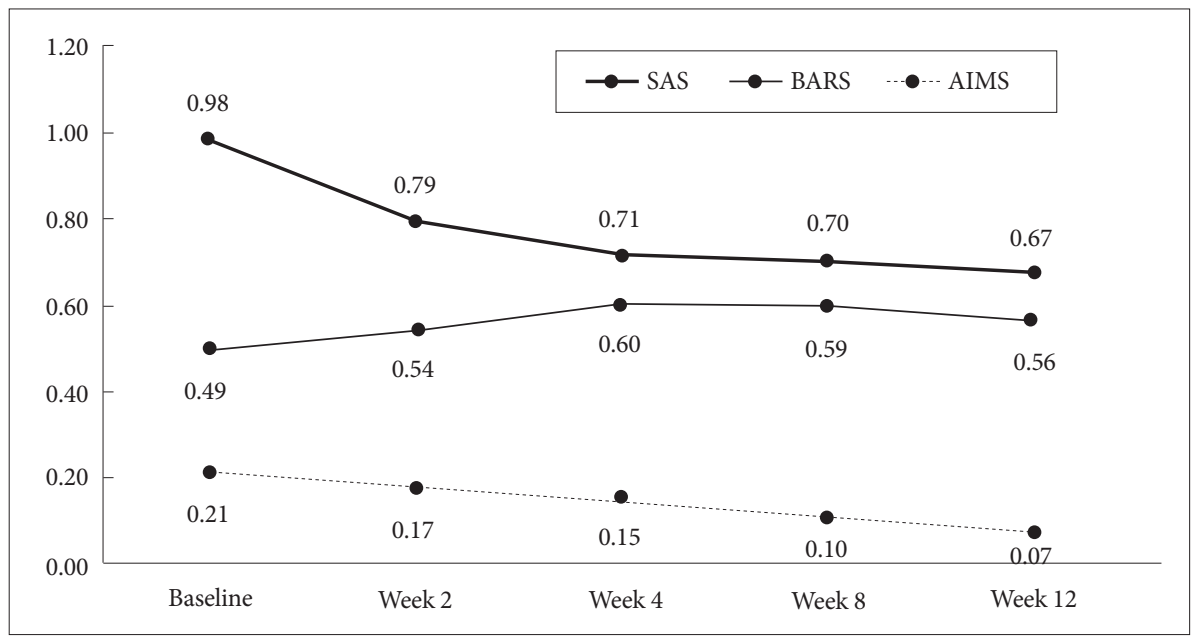

Figure 3. Changes in SAS, BARS, and AIMS scores during study period. SAS: Simpson-Angus Scale, BARS: Barnes Akathisia Rating Scale, AIMS: Abnormal Involuntary Movement Scale. 
Table 4. Comparisons of characteristics between responders and non-responders

\begin{tabular}{|c|c|c|c|}
\hline & $\begin{array}{l}\text { Non-responder }(\mathrm{N}=49) \\
\text { mean } \pm \mathrm{SD} \text { or } \mathrm{N}(\%)\end{array}$ & $\begin{array}{l}\text { Responder }(\mathrm{N}=51) \\
\text { mean } \pm \mathrm{SD} \text { or } \mathrm{N}(\%)\end{array}$ & Significance \\
\hline Age (years) & $44.3 \pm 11.0$ & $42.1 \pm 12.5$ & 0.356 \\
\hline Gender (male) & $21(42.9)$ & $26(51.0)$ & 0.416 \\
\hline Years of schooling & $12.3 \pm 3.0$ & $12.8 \pm 3.3$ & 0.469 \\
\hline Married & $12(24.5)$ & $15(29.4)$ & 0.579 \\
\hline Living alone & $8(16.3)$ & $6(11.8)$ & 0.511 \\
\hline Employed & $10(20.4)$ & $10(19.6)$ & 0.920 \\
\hline \multicolumn{4}{|l|}{ Socio-economic status } \\
\hline High & $3(6.1)$ & $5(9.8)$ & 0.217 \\
\hline Middle & $29(59.2)$ & $36(70.6)$ & \\
\hline Low & $17(34.7)$ & $10(19.6)$ & \\
\hline Age at onset & $28.6 \pm 10.3$ & $29.6 \pm 10.9$ & 0.632 \\
\hline Inpatient & $17(34.7)$ & $31(60.8)$ & $0.009^{*}$ \\
\hline Number of past psychiatric hospitalizations & $3.8 \pm 3.7$ & $3.4 \pm 4.1$ & 0.605 \\
\hline Family history of psychiatric illness & $8(16.3)$ & $5(9.8)$ & 0.332 \\
\hline \multicolumn{4}{|l|}{ Subtypes } \\
\hline Paranoid & $35(71.4)$ & $30(58.8)$ & 0.186 \\
\hline Disorganized & $1(2.0)$ & $2(3.9)$ & 1.000 \\
\hline Catatonic & 0 & $1(2.0)$ & 1.000 \\
\hline Undifferentiated & $13(26.5)$ & $18(35.3)$ & 0.344 \\
\hline Presence of a comorbid medical illness & $18(36.7)$ & $15(29.4)$ & 0.436 \\
\hline \multicolumn{4}{|l|}{ Baseline scores } \\
\hline BPRS & $57.2 \pm 13.6$ & $62.8 \pm 13.7$ & $0.043^{*}$ \\
\hline PANSS-total & $99.2 \pm 26.6$ & $109.5 \pm 22.4$ & $0.038^{*}$ \\
\hline PANSS-positive & $24.9 \pm 6.5$ & $28.0 \pm 7.2$ & $0.025^{*}$ \\
\hline PANSS-negative & $24.4 \pm 8.5$ & $25.5 \pm 6.4$ & 0.440 \\
\hline PANSS-general & $50.2 \pm 14.0$ & $56.3 \pm 10.9$ & $0.016^{*}$ \\
\hline CGI-S & $4.6 \pm 1.1$ & $4.8 \pm 1.0$ & 0.319 \\
\hline GAF & $43.2 \pm 14.8$ & $37.0 \pm 13.0$ & $0.030^{*}$ \\
\hline Mild to moderate severity (PANSS $\leq 85$ ) & $19(38.8)$ & $5(9.8)$ & $0.001^{*}$ \\
\hline \multicolumn{4}{|l|}{ Concomitant antipsychotics } \\
\hline Aripiprazole & $3(6.1)$ & $1(2.0)$ & 0.357 \\
\hline Clozapine & $9(18.4)$ & $3(5.9)$ & 0.069 \\
\hline Olanzapine & $30(61.2)$ & $38(74.5)$ & 0.199 \\
\hline Risperidone/paliperidone & $7(14.3)$ & $9(17.6)$ & 0.787 \\
\hline \multicolumn{4}{|l|}{ Antipsychotics dose (mg/day) } \\
\hline Blonanserin (baseline) & $5.3 \pm 2.8$ & $5.0 \pm 1.9$ & 0.479 \\
\hline Blonanserin (mean) & $9.4 \pm 4.3$ & $13.9 \pm 6.3$ & $<0.001^{*}$ \\
\hline $\begin{array}{l}\text { Concomitant antipsychotics } \\
\text { (mean chlorpromazine equivalent dose) }\end{array}$ & $464.9 \pm 164.5$ & $565.7 \pm 125.1$ & $0.001^{*}$ \\
\hline \multicolumn{4}{|l|}{ Use of other concomitant medications } \\
\hline Mood stabilizer/Anticonvulsants & $7(14.3)$ & $12(23.5)$ & 0.239 \\
\hline Antidepressant & $5(10.2)$ & $3(5.9)$ & 0.483 \\
\hline Benzodiazepine (at baseline) & $25(51.0)$ & $35(68.6)$ & 0.072 \\
\hline Adverse event at baseline & $11(22.4)$ & $20(39.2)$ & 0.070 \\
\hline
\end{tabular}


Table 5. Predictors for response by blonanserin augmentation

\begin{tabular}{|c|c|c|c|c|}
\hline \multirow[b]{2}{*}{ Age } & \multirow{2}{*}{$\frac{\text { Significance }}{0.376}$} & \multirow{2}{*}{$\frac{\mathrm{OR}}{0.981}$} & \multicolumn{2}{|c|}{ 95\% CI (lower-upper) } \\
\hline & & & 0.940 & 1.024 \\
\hline Male & 0.596 & 1.292 & 0.501 & 3.338 \\
\hline Inpatient & 0.596 & 1.375 & 0.424 & 4.460 \\
\hline PANSS $>85$ & $0.007^{*}$ & 10.298 & 1.893 & 56.032 \\
\hline Baseline PANSS-positive & 0.650 & 0.974 & 0.871 & 1.090 \\
\hline Baseline PANSS-general & 0.384 & 0.970 & 0.906 & 1.039 \\
\hline Use of clozapine at baseline & 0.377 & 2.065 & 0.413 & 10.324 \\
\hline Mean dose of blonanserin $\geq 10 \mathrm{mg} /$ day & 0.872 & 1.098 & 0.353 & 3.416 \\
\hline $\begin{array}{l}\text { Mean chlorpromazine equivalent dose of concomitant } \\
\text { antipsychotics }>600 \mathrm{mg} / \text { day }\end{array}$ & $0.014^{*}$ & 4.594 & 1.362 & 15.498 \\
\hline Presence of baseline adverse events & 0.121 & 2.490 & 0.787 & 7.876 \\
\hline
\end{tabular}

${ }^{*} \mathrm{p}<0.05$. PANSS: Positive and Negative Syndrome Scale, OR: odds ratio, CI: confidence interval

mentation strategies using antipsychotics for schizophrenia. Furthermore, several previous studies suggested only a limited benefit from the augmentation with antipsychotics. ${ }^{36-40}$ Some authors ${ }^{18,40}$ suggested that monotherapy in optimum doses already maximizes pharmacologic response, leaving little room for antipsychotic combination for further improvement.

However, in the present study, although the responders (who responded to blonanserin augmentation) were taking $565.7 \pm$ $125.1 \mathrm{mg} /$ day of chlorpromazine equivalent, a dose that nearly corresponds to the upper recommended target range (600 mg/ day) ${ }^{35}$ blonanserin combination afforded additional benefit. The discrepancy between the literature and these findings could be attributed to differences in the study population and treatment regimen. Previous studies that reported a limited benefit from antipsychotics augmentation included mainly treatment-resistant subjects who showed an insufficient response to clozapine $e^{36,37,41-43}$ or had a small sample size of 16-53 patients. ${ }^{39,40,44}$ Conversely, our study excluded patients who had established treatment-resistance and only $12 \%$ of patients were taking clozapine. Furthermore, Correll et al. ${ }^{6}$ reported that the combination of antipsychotics provided benefits over monotherapy in studies lasting longer than 10 weeks, but not in shorter studies.

We found two significant independent predictors of response to blonanserin augmentation: use of high dose concomitant AAPs and severe baseline psychiatric symptoms. Thus, blonanserin augmentation could be profitable for patients who retain severe symptoms despite compliance with a therapeutic regimen of an AAP. This result is in accordance with meta-analyses by Taylor et al. ${ }^{45}$ and Correll et al. ${ }^{6}$ that found significant benefits of the augmentation with a second antipsychotic over a placebo.

However, the results from the present study require interpretation with caution. Because we did not collect data before the start of the intervention, we do not know the characteristics of the patients who were not eligible for the study; for example, several patients discontinued treatment with an AAP before the six-week minimum requirement for enrollment. Our eligibility criteria could have caused selection bias in favor of cases more tolerable to AAP treatment. Moreover, there is a possibility that a low-dose titration regimen could be effective in non-responders. To expound, non-responders could be less tolerable to AAP treatment than responders, and their relative intolerability could cause premature discontinuation of blonanserin, before they had enough time to respond to the blonanserin augmentation. In this situation, non-response may just mean 'intolerability' rather than true 'non-response'. However, two cases of premature discontinuation due to adverse events were reported in both responders and non-responders.

Although there has been a lot of concern regarding the tolerability of antipsychotic combinations, ${ }^{46}$ only $17 \%$ of patients failed to complete the 12-week study. Moreover, premature discontinuation from adverse events was occurred in merely $4 \%$ of patients. As reported in a previous review, ${ }^{32}$ akathisia and extrapyramidal symptoms are frequently reported adverse events. Constipation (20.0\%) was the most common adverse event in this study; however, constipation was likely not related to treatment and occurred in patients who were hospitalized (16 of 20 cases) and/or prescribed anti-Parkinsonian agents (17 of 20 cases). Indeed, lack of activity and/or the anti-Parkinsonian agents could have contributed to the constipation. ${ }^{47}$ Incidence of weight gain in this study (9.0\%) during the 12 weeks was relatively higher than a previous study that reported that $3 \%$ of participants gained weight gain during 6 weeks of blonanserin augmentation therapy. ${ }^{26}$ Further long-term data are needed to confirm the association of blonanserin and weight gain.

There are several limitations that should be considered. 
First, we did not evaluate biochemical metrics such as metabolic parameters (fasting glucose and lipid profiles) and serum prolactin level, nor did we evaluate cognitive functioning, which could have been associated with antipsychotic polypharmacy. ${ }^{30}$ Second, there was no control group, so the improvement observed could have been a result of the placebo effect or the existing AAP, which can continue to make improvements over the course of 6 months. ${ }^{48}$ Third, because most of the patients included in this study had been treated with olanzapine (68.0\%), results from the present study do not infer effectiveness and tolerability of blonanserin augmentation with other AAPs. In addition, the doses of blonanserin during the study period $(11.7 \pm 5.8 \mathrm{mg} /$ day $)$ could have been insufficient.

In summary, the results from the present study suggest that blonanserin augmentation might show additional beneficial effect in patients with schizophrenia who showed an insufficient treatment response to AAP monotherapy. However, the results from the present study are insufficient to derive conclusive clinical recommendations. The treatment response was associated with severe baseline psychiatric symptoms and a relatively high baseline AAP dose. Despite the frequent use of antipsychotic polypharmacy in schizophrenia, there is still only limited evidence for its efficacy. Adequately designed, large, double-blind, placebo-controlled, randomized clinical trials and head-to-head comparisons of different AAPs are needed to address the usefulness of antipsychotic polypharmacy in difficult-to-treat schizophrenic patients. These studies need to include a long-term investigation of safety and druginteractions when combining different AAPs. Furthermore, a further investigation for predictors of response to antipsychotic polypharmacy is needed so that individual cases that will benefit from AAP combinations can be quickly identified. ${ }^{49}$

\section{Acknowledgments}

This study was supported by the Bukwang Pharmaceutical Company, Ltd, Korea. The Bukwang Pharmaceutical Company had no further role in study design; in the collection, analysis, and interpretation of data; in the writing of the report; or in the decision to submit the paper for publication.

\section{REFERENCES}

1. Kirkpatrick B, Fenton WS, Carpenter WT Jr, Marder SR. The NIMHMATRICS consensus statement on negative symptoms. Schizophr Bull 2006;32:214-219.

2. De Hert M, van Winkel R, Wampers M, Kane J, van Os J, Peuskens J. Remission criteria for schizophrenia: evaluation in a large naturalistic cohort. Schizophr Res 2007;92:68-73.

3. Hegarty JD, Baldessarini RJ, Tohen M, Waternaux C, Oepen G. One hundred years of schizophrenia: a meta-analysis of the outcome literature. Am J Psychiatry 1994;151:1409-1416.

4. Lieberman JA, Stroup TS, McEvoy JP, Swartz MS, Rosenheck RA, Perkins DO, et al. Effectiveness of antipsychotic drugs in patients with chronic schizophrenia. N Engl J Med 2005;353:1209-1223.

5. Kim HY, Lee HW, Jung SH, Kang MH, Bae JN, Lee JS, et al. Prescrip- tion patterns for patients with schizophrenia in Korea: a focus on antipsychotic polypharmacy. Clin Psychopharmacol Neurosci 2014;12: 128-136.

6. Correll CU, Rummel-Kluge C, Corves C, Kane JM, Leucht S. Antipsychotic combinations vs monotherapy in schizophrenia: a meta-analysis of randomized controlled trials. Schizophr Bull 2009;35:443-457.

7. Canadian Psychiatric Association. Clinical practice guidelines. Treatment of schizophrenia. Can J Psychiatry 2005;50(13 Suppl 1):7S-57S.

8. Buchanan RW, Kreyenbuhl J, Kelly DL, Noel JM, Boggs DL, Fischer BA, et al. The 2009 schizophrenia PORT psychopharmacological treatment recommendations and summary statements. Schizophr Bull 2010; 36:71-93.

9. Falkai P, Wobrock T, Lieberman J, Glenthoj B, Gattaz WF, Moller HJ, et al. World Federation of Societies of Biological Psychiatry (WFSBP) guidelines for biological treatment of schizophrenia, Part 1: acute treatment of schizophrenia. World J Biol Psychiatry 2005;6:132-191.

10. Health NCCfM. The NICE Guidelines on Core Interventions in the Treatment and Management of Schizophrenia in Adults in Primary and Secondary care. London: British Psychological Society, Royal College of Psychiatrists; 2010.

11. Pandurangi AK, Dalkilic A. Polypharmacy with second-generation antipsychotics: a review of evidence. J Psychiatr Pract 2008;14:345-367.

12. Correll CU, Frederickson AM, Kane JM, Manu P. Does antipsychotic polypharmacy increase the risk for metabolic syndrome? Schizophr Res 2007;89:91-100.

13. Citrome L, Jaffe A, Levine J, Allingham B, Robinson J. Relationship between antipsychotic medication treatment and new cases of diabetes among psychiatric inpatients. Psychiatr Serv 2004;55:1006-1013.

14. Waddington JL, Youssef HA, Kinsella A. Mortality in schizophrenia. Antipsychotic polypharmacy and absence of adjunctive anticholinergics over the course of a 10-year prospective study. Br J Psychiatry 1998; 173:325-329.

15. Joukamaa M, Heliovaara M, Knekt P, Aromaa A, Raitasalo R, Lehtinen V. Schizophrenia, neuroleptic medication and mortality. Br J Psychiatry 2006;188:122-127.

16. Stahl SM. Antipsychotic polypharmacy: evidence based or eminence based? Acta Psychiatr Scand 2002;106:321-322.

17. Freudenreich O, Goff DC. Antipsychotic combination therapy in schizophrenia. A review of efficacy and risks of current combinations. Acta Psychiatr Scand 2002;106:323-330.

18. Barnes TR, Paton C. Antipsychotic polypharmacy in schizophrenia: benefits and risks. CNS Drugs 2011;25:383-399.

19. Chan J, Sweeting M. Review: combination therapy with non-clozapine atypical antipsychotic medication: a review of current evidence. J Psychopharmacol 2007;21:657-664.

20. Suzuki T, Uchida H, Watanabe K, Nakajima S, Nomura K, Takeuchi H, et al. Effectiveness of antipsychotic polypharmacy for patients with treatment refractory schizophrenia: an open-label trial of olanzapine plus risperidone for those who failed to respond to a sequential treatment with olanzapine, quetiapine and risperidone. Hum Psychopharmacol 2008;23:455-463.

21. Molina JD, Toledo-Romero F, Lopez-Rodriguez E, Amorin-Diaz M, Lerma-Carrillo I, Lopez-Munoz F. Augmentation treatment with amisulpride in schizophrenic patients partially responsive to olanzapine. Pharmacopsychiatry 2011;44:142-147.

22. Miyamoto S, Duncan GE, Marx CE, Lieberman JA. Treatments for schizophrenia: a critical review of pharmacology and mechanisms of action of antipsychotic drugs. Mol Psychiatry 2005;10:79-104.

23. Tenjin T, Miyamoto S, Ninomiya Y, Kitajima R, Ogino S, Miyake N, et al. Profile of blonanserin for the treatment of schizophrenia. Neuropsychiatr Dis Treat 2013;9:587-594.

24. Miura S. Clinical evaluation of blonanserin for schizophrenia: a randomized controlled study comparing blonanserin with risperidone. Jpn J Clin Psychopharmacol 2008;11:297-314.

25. Yang J, Bahk WM, Cho HS, Jeon YW, Jon DI, Jung HY, et al. Efficacy 
and tolerability of Blonanserin in the patients with schizophrenia: a randomized, double-blind, risperidone-compared trial. Clin Neuropharmacol 2010;33:169-175.

26. Garcia E, Robert M, Peris F, Nakamura H, Sato N, Terazawa Y. The efficacy and safety of blonanserin compared with haloperidol in acutephase schizophrenia: a randomized, double-blind, placebo-controlled, multicentre study. CNS Drugs 2009;23:615-625.

27. Murasaki M. Clinical evaluation of blonanserin for schizophrenia: a double-blind trial comparing blonanserin with haloperidol. Jpn J Clin Psychopharmacol 2007;10:2059-2079.

28. Kishi T, Matsuda Y, Nakamura H, Iwata N. Blonanserin for schizophrenia: systematic review and meta-analysis of double-blind, randomized, controlled trials. J Psychiatr Res 2013;47:149-154.

29. Takaki M, Okahisa Y, Kodama M, Mizuki Y, Sakamoto S, Ujike H, et al. Efficacy and tolerability of blonanserin in 48 patients with intractable schizophrenia. Acta Neuropsychiatr 2012;24:380-383.

30. Lochmann van Bennekom MW, Gijsman HJ, Zitman FG. Antipsychotic polypharmacy in psychotic disorders: a critical review of neurobiology, efficacy, tolerability and cost effectiveness. J Psychopharmacol 2013;27:327-336.

31. Munro J, Matthiasson P, Osborne S, Travis M, Purcell S, Cobb AM, et al. Amisulpride augmentation of clozapine: an open non-randomized study in patients with schizophrenia partially responsive to clozapine. Acta Psychiatr Scand 2004;110:292-298.

32. Deeks ED, Keating GM. Blonanserin: a review of its use in the management of schizophrenia. CNS Drugs 2010;24:65-84.

33. Preskorn SH. Clinically important differences in the pharmacokinetics of the ten newer "atypical" antipsychotics: Part 2. Metabolism and elimination. J Psychiatr Pract 2012;18:361-368.

34. Vermeir M, Naessens I, Remmerie B, Mannens G, Hendrickx J, Sterkens $\mathrm{P}$, et al. Absorption, metabolism, and excretion of paliperidone, a new monoaminergic antagonist, in humans. Drug Metab Dispos 2008; 36:769-779.

35. Gardner DM, Murphy AL, O'Donnell H, Centorrino F, Baldessarini RJ. International consensus study of antipsychotic dosing. Am J Psychiatry 2010;167:686-693.

36. Honer WG, Thornton AE, Chen EY, Chan RC, Wong JO, Bergmann $\mathrm{A}$, et al. Clozapine alone versus clozapine and risperidone with refractory schizophrenia. N Engl J Med 2006;354:472-482.

37. Freudenreich O, Henderson DC, Walsh JP, Culhane MA, Goff DC. Risperidone augmentation for schizophrenia partially responsive to clozapine: a double-blind, placebo-controlled trial. Schizophr Res 2007;92:90-94.

38. Fleischhacker WW, Heikkinen ME, Olie JP, Landsberg W, Dewaele P, McQuade RD, et al. Effects of adjunctive treatment with aripiprazole on body weight and clinical efficacy in schizophrenia patients treated with clozapine: a randomized, double-blind, placebo-controlled trial. Int J Neuropsychopharmacol 2010;13:1115-1125.

39. Friedman JI, Lindenmayer JP, Alcantara F, Bowler S, Parak M, White L, et al. Pimozide augmentation of clozapine inpatients with schizophrenia and schizoaffective disorder unresponsive to clozapine monotherapy. Neuropsychopharmacology 2011;36:1289-1295.

40. Gunduz-Bruce H, Oliver S, Gueorguieva R, Forselius-Bielen K, D'Souza DC, Zimolo Z, et al. Efficacy of pimozide augmentation for clozapine partial responders with schizophrenia. Schizophr Res 2013; 143:344-347.

41. Chang JS, Ahn YM, Park HJ, Lee KY, Kim SH, Kang UG, et al. Aripiprazole augmentation in clozapine-treated patients with refractory schizophrenia: an 8-week, randomized, double-blind, placebo-controlled trial. J Clin Psychiatry 2008;69:720-731.

42. Weiner E, Conley RR, Ball MP, Feldman S, Gold JM, Kelly DL, et al. Adjunctive risperidone for partially responsive people with schizophrenia treated with clozapine. Neuropsychopharmacology 2010;35:22742283.

43. Cipriani A, Accordini S, Nose M, Purgato M, Girlanda F, Tansella M, et al. Aripiprazole versus haloperidol in combination with clozapine for treatment-resistant schizophrenia: a 12-month, randomized, naturalistic trial. J Clin Psychopharmacol 2013;33:533-537.

44. Assion HJ, Reinbold H, Lemanski S, Basilowski M, Juckel G. Amisulpride augmentation in patients with schizophrenia partially responsive or unresponsive to clozapine. A randomized, double-blind, placebocontrolled trial. Pharmacopsychiatry 2008;41:24-28.

45. Taylor DM, Smith L, Gee SH, Nielsen J. Augmentation of clozapine with a second antipsychotic - a meta-analysis. Acta Psychiatr Scand 2012;125:15-24.

46. Fleischhacker WW, Uchida H. Critical review of antipsychotic polypharmacy in the treatment of schizophrenia. Int J Neuropsychopharmacol 2014;17:1083-1093.

47. Jessurun JG, van Harten PN, Egberts TC, Pijl BJ, Wilting I, Tenback $D E$. The effect of psychotropic medications on the occurrence of constipation in hospitalized psychiatric patients. J Clin Psychopharmacol 2013;33:587-590.

48. Kane JM, Leucht S, Carpenter D, Docherty JP; Expert Consensus Panel for Optimizing Pharmacologic Treatment of Psychotic Disorders. The expert consensus guideline series. Optimizing pharmacologic treatment of psychotic disorders. Introduction: methods, commentary, and summary. J Clin Psychiatry 2003;64(Suppl 12):5-19.

49. Hasan A, Falkai P, Wobrock T, Lieberman J, Glenthoj B, Gattaz WF, et al. World Federation of Societies of Biological Psychiatry (WFSBP) Guidelines for Biological Treatment of Schizophrenia, part 1: update 2012 on the acute treatment of schizophrenia and the management of treatment resistance. World J Biol Psychiatry 2012;13:318-378. 